\title{
Plastid degeneration in Tillandsia (Bromeliaceae) provides evidence about the origin of multilamellar bodies in plants
}

Wouter G. van Doorn ${ }^{1,2}$ and Alessio Papini ${ }^{2 *}$

${ }^{1}$ Mann Laboratory, Department of Plant Sciences, University of California, Davis, California 95616, USA

${ }^{2}$ Dipartimento di Biologia, Università di Firenze, Via La Pira 4, 50132 Florence, Italy, tel.

10 +390552757395; e-mail alpapini@unifi.it

*Corresponding author

${ }^{2}$ Dr. Wouter G. van Doorn passed away on May $16^{\text {th }}, 2015$. He was an expert in autophagy and 15 programmed cell death and laid out the basic idea about this article. He wrote a large part of the introduction and discussion.

The authors declare no conflict of interest 


\begin{abstract}
Vesicle-like structures containing several to numerous concentric membranes, called multilamellar bodies (MLBs), are present both in animal and plant cells. The origin of MLBs in animal cells has been elucidated partially, while that of plant MLBs is unknown. MLBs in plant

5 cells are present in the cytoplasm, at the interface of cytoplasm and vacuole, and inside vacuoles. This suggests that they become transported from the cytoplasm to the vacuole. The function of plant MLBs thus seems transfer of cellular membranes to the vacuole. Although it is often impossible to discern whether they have a single or a double outer membrane, in some examples a double outer membrane is present. This might suggest autophagic/mitochondrial/plastidial 10 origin. Membrane structures similar to those in MLBs have not been described, apparently, in mitochondria. By contrast, structures similar to MLBs are found in autophagous structures and in degenerating chloroplasts and other plastids. The data might suggest the hypothesis that plant MLBs derive from autophagous structures and/or from plastids.
\end{abstract}

15 Key words: autophagy, chloroplast, multilamellar bodies, plastids, vacuole

\title{
Introduction
}

Multilamellar bodies (MLBs) have been shown in animal and in plant cells, and are also found in in protozoa (Paquet et al., 2013). In animals, MLBs contain several concentric membrane layers,

20 and are bound by a single outer membrane. MLBs are found in many cell types, and are involved in storage of proteins and lipids. They also often function in secretion of lipids and other molecules to the cell surface (Schmitz and Müller, 1991; Hariri et al., 2000; Lajoie et al., 2005; 
Paquet et al., 2013). For example, in lung type II alveolar cells, MLBs are secreted to the exterior. This results in the deposition of lipidic surfactant molecules that regulate the surface tension at the air-lung interface (Lajoie et al., 2005). The hydrophobic film that is deposited on the stomach surface also originates from MLBs and so does the hydrophobic water-protective

5 barrier of the skin (Schmitz and Müller, 1991; Raymond et al., 2008; Moreno et al., 2008).

Animal MLBs derive from the trans-Golgi network (Raymond et al., 2008). They also have been suggested to be formed by autophagy (Hariri et al., 2000; Lajoie et al. 2005) MLBs, have been interpreted to store, transport and secrete, and possibly digest, endosomal and/or autophagic cargo (Dermaut et al., 2005).

As in animals, plant MLBs consist of several concentric membranes, packed together in a vesicle-like compartment. Plants MLBs have been observed in the cytosol and in vacuoles, but have apparently not been reported to deposit their cargo in the apoplast. In contrast to MLBs in animals, no information seems available on the origin of the ones in plants. We here discuss a number of possibilities on the basis of observations in Tillandsia (Bromeliaceae) of the anther tapetum, a tissue undergoing degeneration processes in its last phase of development, eventually leading to programmed cell death (Papini et al. 1999). The frequent presence of MLBs in this tissues at different stages of development will be the basis to hypothesize a possible origin of plant MLBs. 
One of the authors collected Tillandsia spp. (mainly Tillandsia albida Mez et Purpus) in Mexico in 1991 and 1997 in Mexico D.F. and in the Hidalgo state. The plants were maintained as living specimens in the Botanical Garden of Florence (Italy) until nowadays. Flowers of Tillandsia were cut a

5 different heights (and different developmental stages) of the inflorescence. Approximately ten flowers were examined at each stage of development. We cut also leaves sections for observing efficient chloroplasts.

We cut transverse sections $(0.5 \mathrm{~mm}$ thickness, about three per flower $)$ of the anthers and the same size of the leaf with a razor blade. These sections were fixed overnight in $1.25 \%$ glutaraldehyde at $4^{\circ} \mathrm{C}$ in $0.1 \mathrm{M}$ phosphate buffer ( $\mathrm{pH} 6.8$ ), then post-fixed in $1 \% \mathrm{OsO}_{4}$ in the same buffer for $1 \mathrm{hr}$. After dehydration in an ethanol series and a propylene oxide step, the samples were embedded in Spurr's epoxy resin (Spurr 1969). Transverse sections approximately $80 \mathrm{~nm}$ thick were cut with Reichert-Jung ULTRACUT E ultramicrotome equipped with a diamond knife. The sections on copper grids were stained with uranyl acetate (Gibbons and Grimstone 1960) and lead citrate (Reynolds 1963), and then observed with a Philips EM300 TEM at $80 \mathrm{kV}$.

\section{Results}

In the tapetum of Tillandsia at the tetrads stage of pollen development some MLBs could be found free in the cytosol, often in contact with small vacuoles (Fig. 1). During a later stage the cytoplasm of the tapetal cells tended to become more electron dense (Fig.s 2 and 3). In this stage many MLBs were observed entering a small vacuole (Fig. 2) or already included in it (Fig. 3). In this latter situation the MLB appeared to have a central area with a lower electron density but always containing membranes. Other membranes not organized as MLBs were observed elsewhere in the vacuole. Vacuoles tended in some cases to fuse together to form larger 
structures containing MLBs (Fig. 4). MLBS proceding from the situation in Fig. 2 to Fig. 3 and 4 appeared to reduce their size. In some cases portion of cytoplasm and MLBs could be individuated contemporaneously within a medium sized vacuole (Fig. 5).

In T. albida leaves, the guard cells of stomata showed normal chloroplasts containing starch and

5 apparently normal thylakoids and some chloroplasts still containing starch but starting to dismantle their membrane system (Fig. 6).

At a later stage of tapetal development concentric membranes in plastids became frequent (Fig. 7). In some rare cases some plastoglobules appeared surrounded by a membrane.

Some cells contained large vacuoles that engulfed large portions of protoplast including apparently organells with a continuous double membrane. Inside the organelle are also membranes (Fig. 9).

Some plastids showed membrane-like structures possibly related to plastoglobuli and membranous structure with some electron-dense areas (Fig. 10). In other plastids concentric very uniform membranes accumulated (Fig. 11).

\section{Discussion}

\section{Form, size and internal structure of plant MLBs; cellular localisation}

Early authors called plant MLBs 'myelin bodies'. Myelin refers to cells around neuronal axes, containing concentric membrane circles. Plants do not contain myelin (Adami and Aschoff, 1906; Nave, 2010). 
Plant MLBs in plants vary in form, size and structure. They are usually round but can also be ovoid and oblong. In our work on tapetal cells in Tillandsia albida the largest diameter varied from 100 to $600 \mathrm{~nm}$ (Papini et al., 1999), but diameters up to $2400 \mathrm{~nm}$ have been reported (Schmitz and Müller, 1991; Fernández et al., 2013). The internal structure of plant MLBs varies

5 in two ways: a) the number of stacked membranes and b) the membrane arrangement.

Membranes can be single or double. Examples of single membranes are found in plastids shown in Fig. 1. Double membranes were described in Sarcocapnos pulcherrima pollen grains (Fernández al. 2013). The origin of double membranes is not known. They might derive, for example, from degradative stages of mitochondria and/or plastids.

The MLBs shown in Fig. 1 are localised in the cytosol. Other MLBs have been found at the interface of cytosol and vacuoles, whereby they apparently protrude into the vacuole (Fig. 2). In still other examples the MLBs are observed inside vacuoles (Fig. 3,4). This sequence might suggest that MLBs in the cytosol can be transferred to vacuoles, where they become degraded. Plant MLBs also have been shown to become engulfed by autophagous structures (see below), which likely result in their degradation inside this structure.

\section{Are MLBs formed by autophagy?}

Plant macroautophagy is different from that in animals. In animal cells a portion of the cytoplasm becomes surrounded by a double-membrane-bound structure that does not contain

20 hydrolases. After sequestering a portion of the cytoplasm this organelle merges with a lysosome, which delivers hydrolases involved in breakdown of the portion of the cytoplasm. Thus in animals one phase of autophagy does not yet entail degradation. In plants the macroautophagous 
organelle contains hydrolases before sequestering a portion of the cytoplasm. Fig. 9 depicts an example of a plant autophagosome/autolysosome that sequesters portions of the cytosol, apparently containing organelles. The engulfed organelle has a double membrane, so might be plastidic or mitochondrial in origin. Inside this organelle are some more (double) membranes.

5 Similar structures were found by Rose et al. (2006) in isolated starving Arabidopis thaliana cell. Such an autophagic process might lead to a structure containing several concentric membranes, thus a MLB. However, it is not known how long these membranes might persist in such an autolytic vacuole. Plant macroautophagy tends to results in rather rapid breakdown of the sequestered material (van Doorn and Papini, 2013). If this is true, it would mean that plant autophagy will likely not add long-lived membranes to MLBs. If so, this would be an argument against an autophagous origin of MLBs. It cannot be excluded, however, that some membranes are hard to degrade and thus persist, hence that MLBs can - in principle - derive from macroautophagy, for instance in cells subjected to programmed cell death, as MLBs appearing in the scutellum of germinated wheat grains (Dominguez et al., 2012). might be sequestered by macroautophagy (van Doorn and Papini, 2013). A possible example is shown in Fig. 5, where a macroautophagous structure has sequestered a portion of the cytoplasm and a MLB as well.

\section{MLBs derive from plastids?}

Several authors noted a coincidence between chloroplast degradation during leaf senescence and the presence of multilamellar bodies in the cytoplasm or vacuole (Hurkman and 
Kennedy, 1975). Fig. 6 shows an example of a chloroplast. The internal membranes are arranged in thylakoids and grana. A thylakoid consists of two membranes closely positioned together, similar to the structure of the ER. Grana are stacks of thylakoids. At an early stage of disintegration the internal membranes structure changes, while plastoglobuli, electron dense

5 bodies mainly containing lipids and proteins, appear or increase in number, as shown also by Evans et al. (2010), Biswal et al. (2013) and Sakuraba et al. (2014). The membranes in such plastids may show one major membrane swirl (Dennis et al. 1967) or several such swirls (Evans et al. 2010). In other examples of late stage chloroplasts only few membranes are left (Butler and Simon, 1971; Hurkman, 1979; Inada et al., 1998). During late phases of internal chloroplast degradation the organelle becomes considerably smaller (Ljubešic, 1968).

TEM micrographs were interpreted to show that whole chloroplasts, at some stage of internal breakdown, can be transported to vacuoles (Wrischer, 1973; Wittenbach et al., 1982; Minamikawa et al., 2001). However, these data are not convincing, as the location of the vacuolar membrane was not demonstrated. It therefore remains to be unequivocally demonstrated that whole chloroplasts can be transported to vacuoles (van Doorn and Papini, 2013).

The ultrastructure of chloroplasts and other plastids might suggest that they become MLBs. This appears, for example, in Tillandsia tapetum cells. The plastid in Fig. 7 shows several plastoglobuli and a concentric arrangement of membranes. These double membranes, which are 20 similar to thylakoids, enclose relatively electron-dense material. In between the double membranes the plastid stroma is more electron-translucent. The plastid at the lower side of Fig. 8 shows plastoglobuli and a circular membrane structure similar to the one in Fig. 7. Above this plastid is another with only two plastoglobuli in the plane of section. This plastid has a few 
circular double membranes.Circular or bent membranes structures in plastids were found also in genera other than Tillandsia. As for plastids containing plastoglobuli of various size in a senescing Nicotiana rustica leaf (Ljubešic, 1968). Some circular membranes were also found in chloroplasts of senescing Arabidopsis thaliana leaves (Evans et al., 2010). Stacks of apparently

5 rolled-up thylakoids have also been observed in chromoplasts of Narcissus pseudonarcissus flowers. These stacks consisted of about 5-10 double membranes, situated at the periphery of the organelle (Al-Babili et al., 1999). In chromoplasts of Capsicum annuum fruit single circular thylakoid sheets were observed as well as configurations of sheets which were either linear or rolled-up (Spurr and Harris, 1968, their Figs. 12-15; Laborde and Spurr, 1973, their Figs. 2, 7, 8, $12,13)$.

Fig. 10 and 11 exhibit plastids with what are apparently plastoglobuli from which the electron-dense material (lipid) has been removed partially. Membrane-like structures have become visible. Similar membranous structures were found by Evans et al. (2010) in Arabidopsis mesophyll. Plastoglobuli have been associated not with membranes but with a single sheet of phospholipids, a half-membrane (Bréhélin et al., 2007; Lundquist et al., 2013). It is not clear if half membranes might be part of the typical rolled-up structures in MLBs. Lichtenthaler and Peveling (1967) showed membranous material in two organelles, most probably plastids as they also contain plastoglobuli. Such membraneous material might consist of half-membranes.

\section{Do MLBs derive from mitochondria?}

The fate of plant mitochondria is still an enigma. A previous investigation in Dendrobium suggested that the internal mitochondrial membranes disappear during late stages of 
development (Kirasak et al., 2010). These data do not exclude that plant mitochondria can also become degraded in vacuoles, and are transported to the organelle through autophagy, as shown by Li et al. (2014). Nonetheless, concentric membranes have apparently not been shown in mitochondria, or in autophagous structures that engulf mitochondria. increased in size, and ended as a vacuole-like organelle. Mitochondria at late stages of development apparently did not show an increase in internal membrane profiles (Kirasak et al., 2010). These data mean that it is unlikely that MLBs derive from mitochondria.

\section{Other possible sources of MLBs}

Peroxisomes apparently have not been found to contain concentric membrane structures similar to MLBs, and are therefore likely not precursors. MLBs also are probably not produced by ER membranes as no concentric arrangements of ER have apparently been reported inside the cytosol, and autophagous structures engulfing ER also seems not reported to date. Golgi bodies contain membranes that are often curved, but again no intermediate stages have apparently been reported of Golgi and MLB. This suggests that that MLBs probably do not derive from ER or Golgi bodies.

\section{Conclusions}

20 The data suggest that MLBs in plants serve to transport membranes to vacuoles, where they will be degraded. This is quite different from the function in animals which often entails deposition to the cell exterior. 
The origin of plant MLBs is as yet unknown. The present data seem not to exclude any possible origin. It is here suggested that none of the present data favour the idea that MLBs derive from the ER, from Golgi bodies, or from mitochondria. There is preliminary evidence, it seems, suggesting that MLBs are produced by autophagy, but the role of autophagy might also

5 be limited to the final stage of MLB degradation, whereby fully developed MLBs are taken up by an autophagous structure. Other data suggest the hypothesis that MLBs derive from plastids. The main argument is that structures resembling MLBs are often observed in degenerating chloroplasts and other plastids.

\section{Acknowledgements}

We thank Gabriele Tani and Pietro Di Falco for their fundamental laboratory support. Research funded by the Italian Ministry of the University (MIUR-Fondi di Ateneo) 


\section{References}

Adami JG, Aschoff L. 1906. On the myelins, myelin bodies and potential fluid crystals of the organism. Proceedings of the Royal Society of London. Series B 78, 359-368.

Al-Babili S, Hartung W, Kleinig H, Beyer P. 1999. CPTA modulates levels of 5 carotenogenic proteins and their mRNAs and affects carotenoid and ABA content as well as chromoplast structure in Narcissus pseudonarcissus flowers. Plant Biology 1, 607-612.

Biswal B, Krupinksa K, Biswal UC. 2013. Plastid development in leaves during growth and senescence. Springer, Dordrecht, The Netherlands.

Bréhélin C, Kessler F, van Wijk KJ. (2007) Plastoglobules: versatile lipoprotein particles in plastids. Trends in Plant Science 12, 260-266.

Brighigna L, Papini A. 1993. The ultrastructure of the tapetum of Tillandsia albida Mez et Purpus. Phytomorphology 43, 261-275.

Butler RD, Simon EW. 1971. Ultrastructural aspects of senescence in plants. In: BL Strehler, Ed. Advances Gerontological Research 3, 73-129.

Colquhoun AJ, Hillman JR, Crewe C, Bowes BG. 1975. An ultrastructural study of the effects of abscisic acid in senescence of leaves of radish (Raphanus sativus L.). Protoplasma 84, $205-221$.

Dennis DT, Stubbs M, Coulate TP. 1967. The inhibition of Brussels sprout leaf senescence by kinins. Canadian Journal of Botany 45, 1019-1024.

\section{Dermaut B, Norga KK, Kania A, Verstreken P, Pan H, Zhou Y, Callaerts P, Bellen} H. 2005. Aberrant lysosomal carbohydrate storage accompanies endocytic defects and neurodegeneration in Drosophila benchwarmer. Journal of Cell Biology 170, 127-139.

Domínguez F, Moreno J, Cejudo FJ. 2012. The scutellum of germinated wheat grains undergoes programmed cell death: identification of an acidic nuclease involved in nucleus dismantling. Journal of Experimental Botany 63, 5475-5485. 
Evans IM, Rus AM, Belanger EM, Kimoto M, Brusslan JA. 2010. Dismantling of Arabidopsis thaliana mesophyll cell chloroplasts during natural leaf senescence. Plant Biology 12, 1-12.

Fernández MC, Pérez-Gutierrez MA, Suarez-Santiago VN, Salinas-Bonillo MJ,

5 Romero-García AT. 2013. Multilamellar bodies linked to two active plasmalemma regions in the pollen grains of Sarcocapnos pulcherrima. Biologia Plantarum 57, 298-304.

Gibbons IR and Grimstone AV. 1960. On the flagellar structure in certain flagellate. $J$. Biophy. Biochem. Cytol. 7, 697-716.

Hariri M, Millane G, Guimond P, Guay G, Dennis JW, Nabi IR. 2000. Biogenesis of multilamellar bodies via autophagy. Molecular Biology of the Cell 11, 255-268.

Harris WM, Spurr AR. 1968. Ultrastructure of chloroplasts and chromoplasts in Capsicum annuиm. I. Thylakoid membrane changes during fruit ripening. American Journal of Botany 55, 1210-1224.

Hurkman WJ. 1979. Ultrastructural changes of chloroplasts in attached and detached, aging primary wheat leaves. American Journal of Botany 66, 64-70.

Hurkman WJ, Kennedy GS. 1975. Ultrastructural changes of chloroplasts in aging tobacco leaves. Indiana Academy of Sciences 85, 89-95.

Inada N, Sakai A, Kuroiwa H, Kuroiwa T. 1998. Three-dimensional analysis of the senescence program in rice (Oryza sativa L.) coleoptiles: investigations by fluorescence microscopy and electron microscopy. Planta 206, 585-597.

Kirasak K, Ketsa S, Imsabai W, van Doorn WG. 2010. Do mitochondria in Dendrobium petal mesophyll cells form vacuole-like vesicles? Protoplasma 241, 51-61.

Lajoie P, Guay G, Dennis JW, Nabi IR. 2005. The lipid composition of autophagic vacuoles regulates expression of multilamellar bodies. Journal of Cell Science 118, 1991-2003. 
LaBorde JA, Spurr AR. 1973. Chromoplast ultrastructure as affected by genes controlling grana retention and carotenoids in fruits of Capsicum annuum. American Journal of Botany 60, 736-744.

Li F, Chung T, Vierstra RD. 2014. Autophagy 11 plays a critical role in general 5 autophagy- and senescence-induced mitophagy in Arabidopsis. Plant Cell 26, 788-807.

Lichtenthaler HK, Peveling E. 1967. Plastoglobuli in verschiedenen Differenzierungsstadien der Plastiden bei Allium cepa L. Planta 72, 1-13.

Ljubešic N. 1968. Feinbau der Chloroplasten während der Vergilbung und Wiederergrünung der Blätter. Protoplasma 66, 368-379.

Lundquist PK, Poliakov A, Giacomelli L, Friso G, Appel M, McQuinne RP, Krassnoff SB, Rowland E, Ponnala L, Sun Q, van Wijk KJ. 2013. Loss of plastoglobule kinases $\mathrm{ABC} 1 \mathrm{~K} 1$ and $\mathrm{ABC} 1 \mathrm{~K} 3$ causes conditional degreening, modified prenyl-lipids, and recruitment of the jasmonic acid pathway. Plant Cell 25, 1818-1839.

Minamikawa T, Toyooka K, Okamoto T, Hara-Nishimura I, Nishimura M. 2001. Degradation of ribulose-bisphosphate carboxylase by vacuolar enzymes of senescing French bean leaves: immunocytochemical and ultrastructural observations. Protoplasma 218, 144-153.

Młodzianowski F, Kwintiewicz M. 1973. The inhibition of kohlrabi chloroplast degeneration by kinetin. Protoplasma 76, 211-226.

Moreno R, Lardennois C, Drouin-Garraud V, Verspyck E, Marret S, Laquerrière A. 2008. Prenatal revelation of Niemann-Pick disease type C in siblings. Acta Paediatrica 97, $1136 \mathrm{e} 9$.

Nave KA. 2010. Myelination and the trophic support of long axons. Nature Reviews Neuroscience 11, 275-283

Papini A, Mosti S, Brighigna L 1999. Programmed cell death events in the tapetum 25 development of Angiosperms. Protoplasma 207, 213-221.

Papini A, Mosti S, van Doorn WG. (2014) Classical macroautophagy in Lobivia 
rauschii (Cactaceae) and possible plastidial autophagy in Tillandsia albida (Bromeliaceae) tapetum cells. Protoplasma 251, 719-725.

Paquet VE, Lessire R, Domergue F, Fouillen L, Filion G, Sedighi A, Charette SJ.

5 2013. Lipid composition of multilamellar bodies secreted by Dictyostelium discoideum reveals their amoebal origin. Eukaryotic Cell 12, 1326-1334.

Raymond AA, Gonzalez de Peredo A, Stella A, Ishida-Yamamoto A, Bouyssie D, Serre G, Monsarrat B, Simon M. 2008. Lamellar bodies of human epidermis: proteomics characterization by high throughput mass spectrometry and possible involvement of CLIP-170 in their trafficking/secretion. Mol. Cell. Proteomics 7, 2151-2175.

Reynolds ES. 1963. The use of lead citrate at high pH as an electron-opaque stain for electron microscopy. J. Cell Biol. 17, 208-212.

Rose TL, Bonneau L, Der C, Marty-Mazars D, Marty F. 2006. Starvation-induced expression of autophagy-related genes in Arabidopsis. Biology of the Cell 98, 53-67.

Sakuraba Y, Lee SH, Kim YS, Park OK, Hörtensteiner S, Nam-Chon P. 2014. Delayed degradation of chlorophylls and photosynthetic proteins in Arabidopsis autophagy mutants during stress-induced leaf yellowing. Journal of Experimental Botany 65, 3915-3925.

Schmitz G, Müller G. 1991. Structure and function of lamellar bodies, lipid-protein 20 complexes involved in storage and secretion of cellular lipids. Journal of Lipid Research 32:1539-1570.

Spurr AR. 1969. A low viscosity epoxy resin embedding medium for electron microscopy. Journal of Ultrastructural Research 26, 31-43.

van Doorn WG, Papini A. 2013. Ultrastructure of autophagy in plant cells: a review. Autophagy 9, 1922-1936.

Wittenbach VA, Lin W, Hebert RR. 1982. Vacuolar localization of proteases and degradation of chloroplasts in mesophyll protoplasts from senescing primary wheat leaves. Plant Physiology 69, 98-102. 
bioRxiv preprint doi: https://doi.org/10.1101/038158; this version posted January 28, 2016. The copyright holder for this preprint (which was not certified by peer review) is the author/funder, who has granted bioRxiv a license to display the preprint in perpetuity. It is made available under 16

Wrischer M. 1973. Protein crystalloids in the stroma of bean plastids. Protoplasma 77, 141-150. 


\section{Figure legends}

Fig. 1. Multilamellar bodies in the cytosol (asterisk) in Tillandsia albida tapetum cell. Bar $=500$ nm. Fig. 2. Multilamellar bodies entering the vacuole in Tillandsia albida tapetum cell. Bar $=1$ $\mu \mathrm{m}$. Fig. 3. A single MLB in a vacuole Bar $=500 \mathrm{~nm}$. Fig. 4. Vacuoles containing MLBs

5 merging together Bar $=500 \mathrm{~nm}$. Fig. 5. A portion of the cytoplasm and an MLB in a plant autophagosome/autolysosome in a Tillandsia albida tapetum cell. Bar $=500 \mathrm{~nm}$.

Fig. 6. T. albida stomatal guard cell. Normal chloroplast (asterisk) early stages of a chloroplast degeneration (arrow). Bar $=200 \mathrm{~nm}$.

Fig. 7. Concentric membranes in plastids of T. albida tapetum cells. Bar $=200 \mathrm{~nm}$. Fig. 8. As in

10 Fig. 7, but Some plastoglobules (arrow) appear surrounded by a membrane. Bar $=200 \mathrm{~nm}$.

Fig. 9. T. albida tapetum cells. Double membranes of MLBs and autophagous sequestration of plastids or MLBs. Autophagosome/autolysosome. The engulfed portions of the protoplasm contain what seem organelles, possibly plastids, with a continuous double membrane (arrow). Inside the organelle are also membranes. Bar $=2 \mu \mathrm{m}$.

15 Fig. 10. Concentric membranes in plastids of Tillandsia albida tapetum cells. Membrane-like structures possibly related to plastoglobuli (lower part of the micrograph) and membranous structure with some electron-dense areas (higher part of the micrograph). Bar = $500 \mathrm{~nm}$. Fig. 11. Concentric membranes in plastids of Tillandsia albida tapetum cells. Accumulated membranes that are rather uniform electron-dense form in a plastid (asterisk). Bar $=500 \mathrm{~nm}$. 

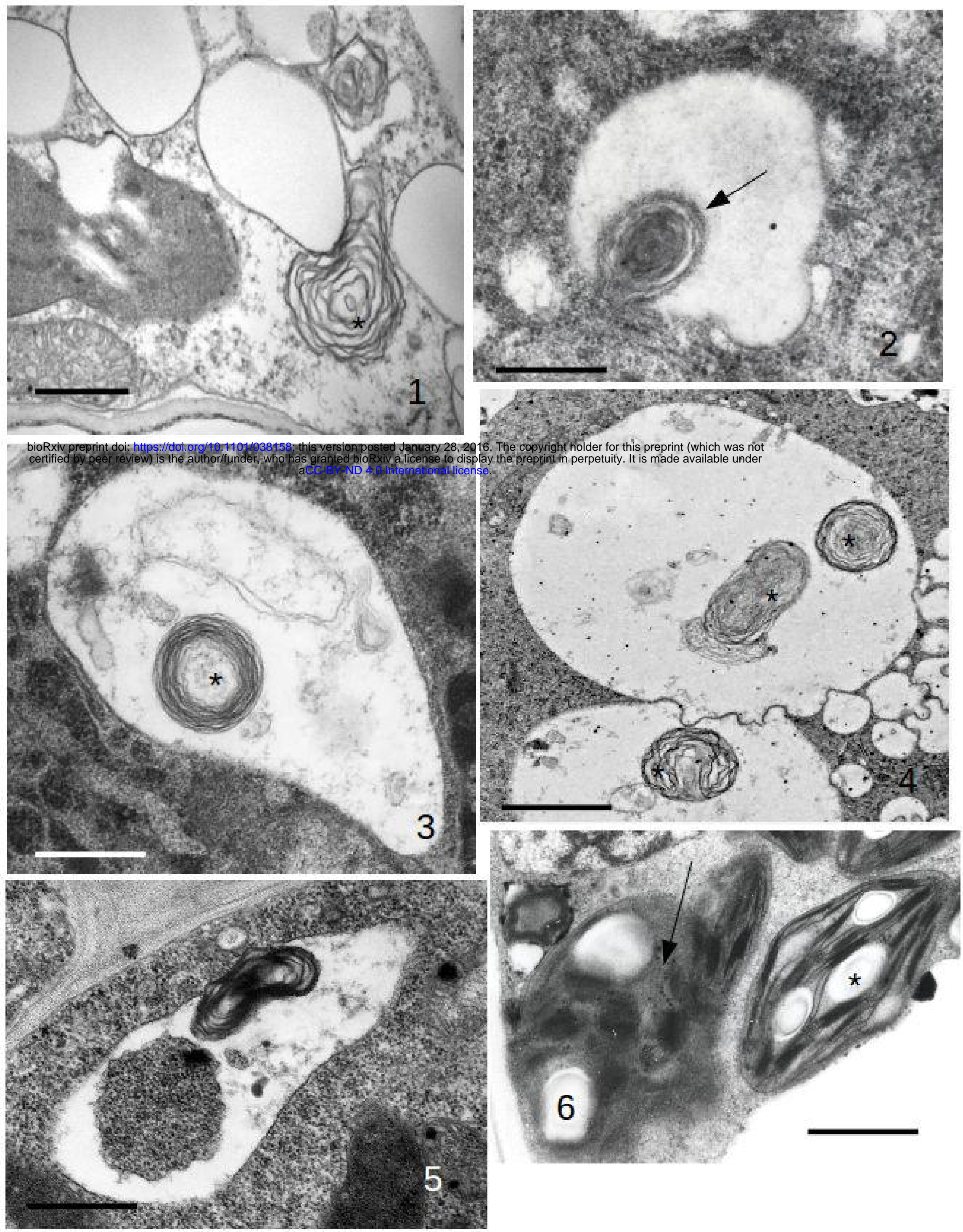

\section{6}




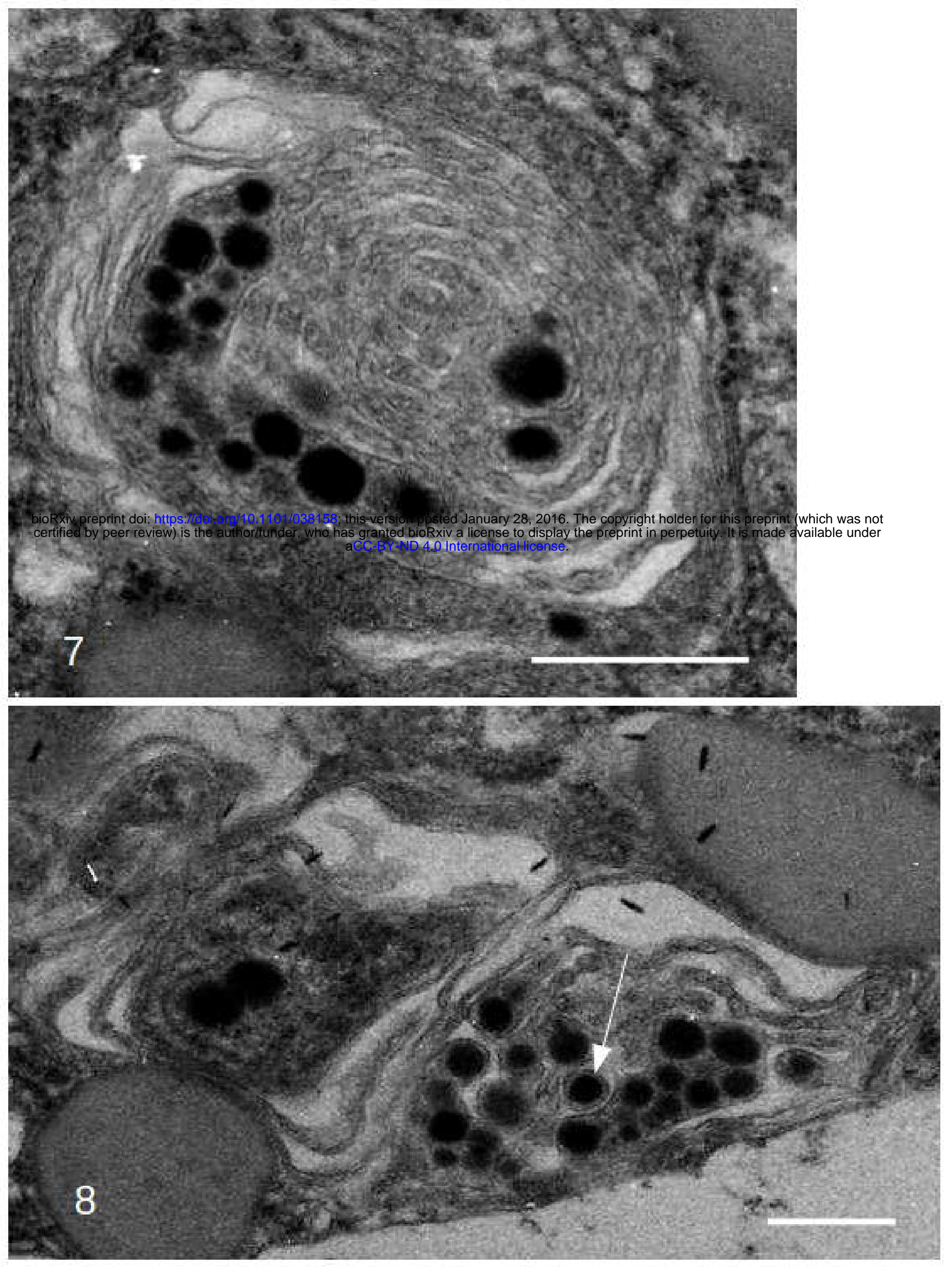



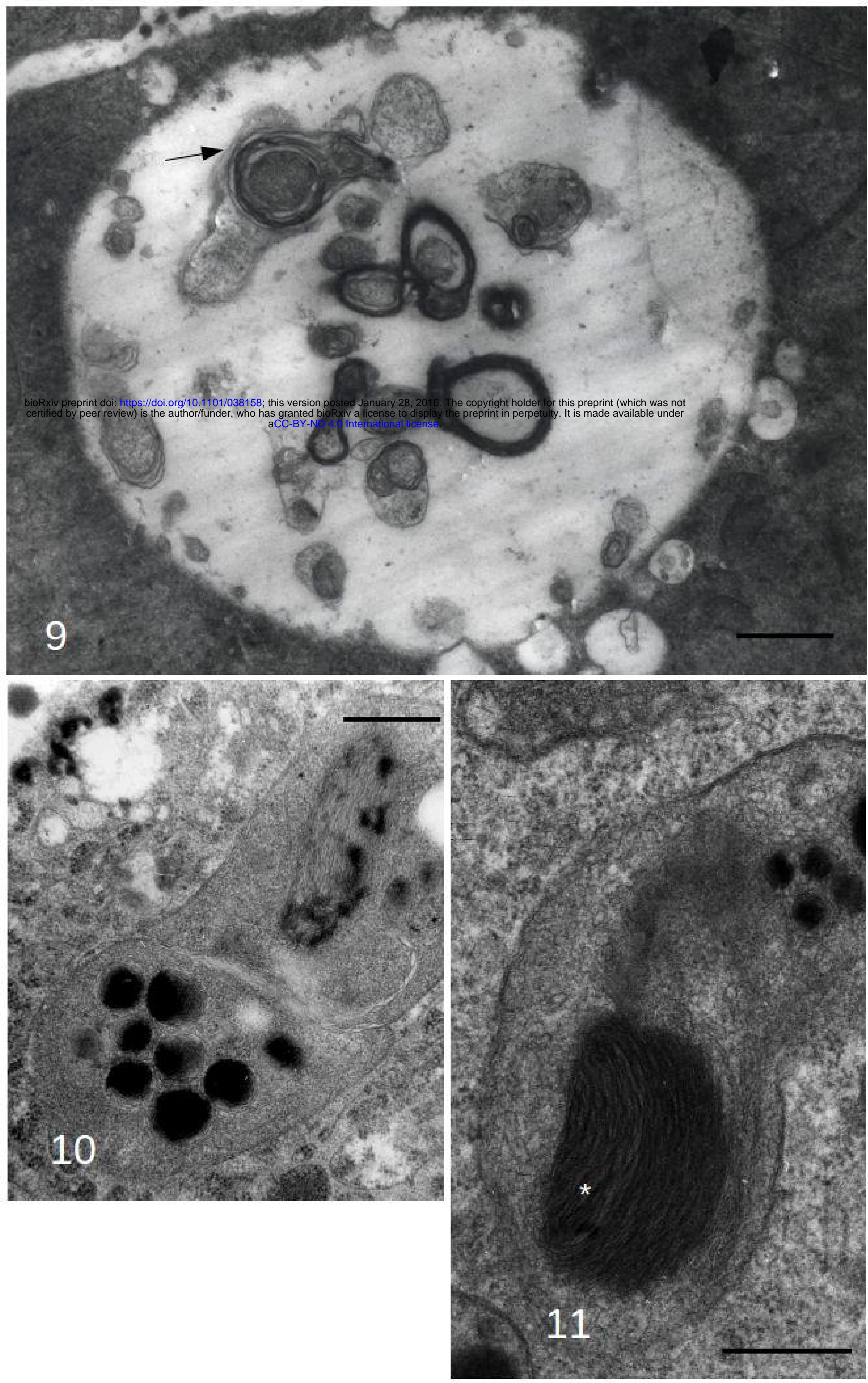